\title{
DYNAMICS OF CHANGES IN TEMPERATURE OF BATCH STERILIZERS WITH BACKPRESSURE
}

\author{
O. Klymenko ${ }^{1}$, V. Petrenko ${ }^{2}$, V. Tregub ${ }^{3}$ \\ ${ }^{1}$ National University of Food Technologies, Kyiv, Ukraine \\ Copyright (C) 2014 by author and the journal -Automation technological and business - processesll. \\ This work is licensed under the Creative Commons Attribution International License (CC BY). \\ http://creativecommons.org/licenses/by/4.0/
}

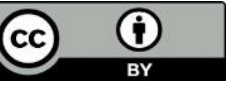

ONAFT

Open Access

Abstract: The article describes the construction of dynamic subsystem logical and dynamic model for batch sterilizer with counter-pressure needed for the construction of programmer.

To describe the dynamics of counter-pressure autoclave is used mathematical method that takes into account the sequence of the autoclave.

Modeling scheme for areas of heating and shutter, and cooling area are programmed in MatLab with the the heat balance equation. There are circuit modeling temperature changes in banks in areas of heating and shutter speed and cooling section.

Keywords: Dynamic subsystem, sterilizer, autoclave with counter-pressure, heat balance.

Introduction. Development of the programmer for the automated control batch sterilizer to implement programmed in accordance with technological requirements change in temperature of the operating environment in autoclave requires quite accurate dynamic model.

Research Methodology. To describe the dynamics of counter-pressure autoclave is used a mathematical method, given a sequence of autoclave [1]. Once downloaded, the autoclave is filled with water so that all the canned foods were covered by it. Then the water is heated by direct feed of saturated steam into the water. When the temperature reaches 80 degrees, the autoclave is closed and filled with water to reach the top level. Heat continue to sterilization temperature, and pressure increases with increasing of the temperature in an autoclave.

The pressure is regulated by using the drain valve. Sterilization temperature is maintained in the apparatus during the time set by regulations. Cooling starts after this time. For this purpose stops steam supply in an autoclave and starts supply of cold water. To preserve the containers from damage initially cooling is performed with constant pressure in the machine. Pressure is maintained by air supply. Discharge of water followed by cooling starts when the temperature drops to 80 degrees respectively. It stops at the temperature of water equal to 40 degrees respectively. When the apparatus is empty, the containers must be removed.

In constructing the mathematical model made the following assumptions: enthalpy of steam $i$ " is considered as a constant [2], heat capacity of water $c_{b}$ is accepted as the average for a range of temperatures in the autoclave. Since the autoclave is well insulated, the heat losses into the environment are minor and are not included in the calculation. Discharge of water for areas of heating and shutter occurs only when pressure reduction is necessary, according to the water flow by discharging is low value and thus heat losses are small and can be neglected. Air is supplied (if necessary) only to maintain the pressure and does not affected on the heat balance. Water consumption for discharging is calculated as a constant value when the valve is $50 \%$. The temperature of the cooling water may vary depending on the season, but during the process it remains unchanged.

The amount of heat that accumulated in the water in the middle of sterilizer $Q_{w}$, can be determined from the balance equation [3]:

$$
\frac{d Q w}{d \tau}=\Phi_{s t}-\Phi_{c}-\Phi_{e n v}-\Phi_{d w}
$$

where $\Phi_{s t}$ - heat flow entering the sterilizer with steam; $\Phi_{c}, \Phi_{e n v}, \Phi_{d w}$ - heat flows to heating cans, heat losses into the environment and to discharge of water respectively.

$$
k_{c . w} \cdot \frac{d t_{w}}{d \tau}=\Phi_{s t}-\Phi_{c}-\Phi_{e n v}-\Phi_{d w}
$$

where $t_{w}$ - the water temperature, $k_{c . w}$ - coefficient of capacitance of water that is heated.

Taking into account above assumptions, equation (2) can be written as follows: 
In its turn

$$
k_{c . w} \cdot \frac{d t_{w}}{d \tau}=\Phi_{s t}-\Phi_{c}
$$

$$
\Phi_{s t}=G_{s t} i^{\prime \prime}
$$

where $G_{s t}$ - the flow of steam, $i^{\prime \prime}$ - enthalpy of steam;

$$
\Phi_{c}=K \cdot F \cdot\left(t_{w}-t_{c}\right)
$$

where $t_{c}$ - the temperature cans, $K$ - heat transfer coefficient, $F$ - surface area of the cans. So,

$$
m_{w} c_{w} \cdot \frac{d t_{w}}{d \tau}=G_{s i} i^{\prime \prime}-K \cdot F \cdot\left(t_{w}-t_{c}\right)
$$

where $m_{w}$ - mass of water, $c_{w}$ - heat capacity of water, or

$$
\frac{m_{w} c_{w}}{K \cdot F} \cdot \frac{d t_{w}}{d \tau}+t_{w}=\frac{i^{\prime \prime}}{K \cdot F} \cdot G_{s t}+t_{c}
$$

The amount of heat that accumulated in the water in the middle of sterilizer $Q_{w}$ for cooling stage can be determined from the balance equation:

$$
\frac{d Q_{w}}{d \tau}=\Phi_{c w}+\Phi_{c}+\Phi_{a i r}-\Phi_{d w}
$$

where $\Phi_{c w}$ - heat flow entering the sterilizer with cooling water, $\Phi_{c}$ - heat flow from the heated cans, $\Phi_{\text {air }}-$ heat flow introduced by air and $\Phi_{d w}$ - heat losses in the discharge of water from the autoclave.

$$
k_{c . w} \cdot \frac{d t_{w}}{d \tau}=\Phi_{c w}+\Phi_{c}+\Phi_{a i r}-\Phi_{d w}
$$

where $t_{w}$ - the water temperature, $k_{c . w}$ - coefficient of capacitance of water that cooled.

Taking into account assumptions above equation (9) can be written as follows:

$$
k_{c . w} \cdot \frac{d t_{w}}{d \tau}=\Phi_{c w}+\Phi_{c}-\Phi_{d w}
$$

In its turn

$$
\Phi_{c w}=G_{c w} \cdot c_{w} \cdot t_{c w}
$$

where $G_{c w}$ - the flow of cooling water, $c_{w}$ - heat capacity of water, $t_{c w}$ - the temperature of the cooling water.

$$
\Phi_{d w}=G_{d w} \cdot c_{w} \cdot t_{w}
$$

where $G_{c w}$ - the flow of the discharge of water.

$$
G_{c w}=S \cdot v
$$

where $S$ - the cross sectional area of the valve, $S=\pi \cdot r^{2}, r$ - radius of the valve; $v$ - the flow rate, $v^{2}=2 \cdot g \cdot H, H$ height of the water column.

In its turn,

$$
\Phi_{c}=K \cdot F \cdot\left(t_{c}-t_{w}\right)
$$

$$
\begin{array}{r}
m_{w} \cdot c_{w} \cdot \frac{d t_{w}}{d \tau}=G_{c w} \cdot c_{w} \cdot t_{c w}+K \cdot F \cdot\left(t_{c}-t_{w}\right)-G_{d w} \cdot c_{w} \cdot t_{w} \\
\frac{m_{w} \cdot c_{w}}{K \cdot F+G_{d w} \cdot c_{w}} \cdot \frac{d t_{w}}{d \tau}+t_{w}=\frac{c_{w} \cdot t_{c w}}{K \cdot F+G_{d w} \cdot c_{w}} \cdot G_{c w}+\frac{K \cdot F \cdot t_{c}}{K \cdot F+G_{d w} \cdot c_{w}}
\end{array}
$$

Scheme of modeling of areas of heating and shutter is programmed in MatLab [4] and shown in Figure 1, and cooling area - in Figure 2.

Temperature change in the banks is modeled with Subsystem. It is necessary for simulation of autoclave on heat-shutter areas (Figure 3) and cooling area (Figure 4). Subsystem functions are used to implement mathematical equations in an environment MatLab. Temp.banok unit is responsible for modeling of temperature changes in banks in areas of heating and shutter, and block temp.banok1 - in cooling area. 


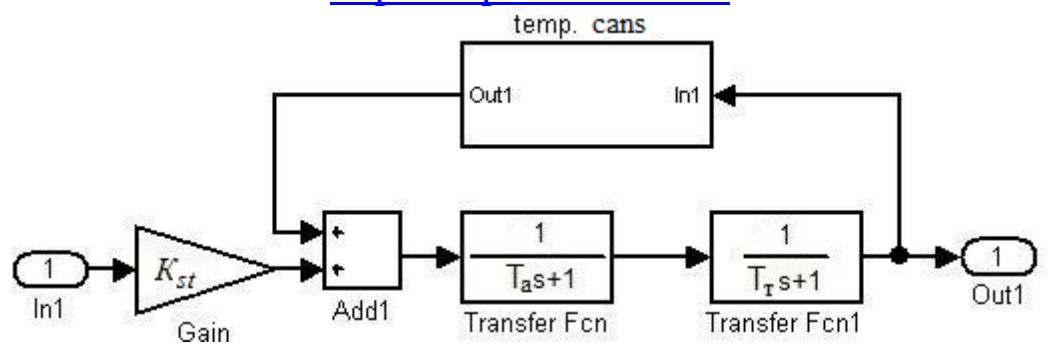

Where In1 - entry corresponding to the flow of steam; $K_{\text {st }}$ - transfer coefficient of steam, $K_{s t}=\frac{i^{\prime \prime}}{K \cdot F} ; T_{a}-$ time constant of autoclave, $T_{a}=\frac{m_{w} c_{w}}{K \cdot F} ; T_{T}$ - time constant of the thermometer; Outl - output corresponding to the water temperature in an autoclave.

Fig.1 - Scheme of modeling of areas of heating and shutter in MatLab

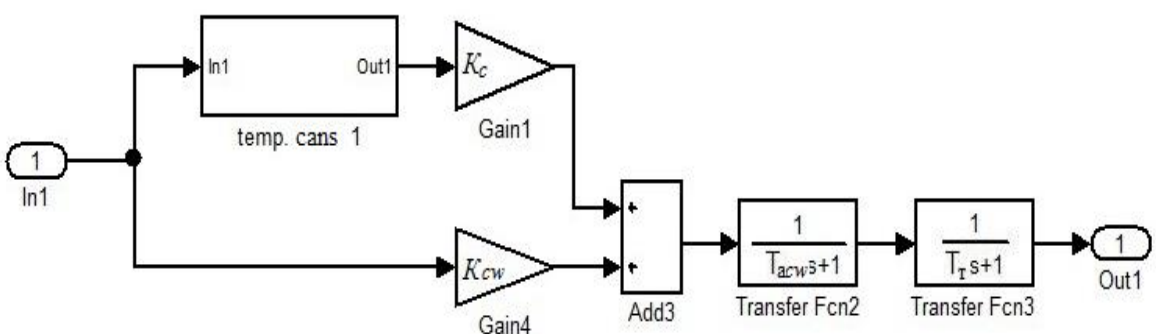

Where In1 - entry corresponding to the flow of cooling water; $T_{a c w}$ - time constant of autoclave, $T_{a c w}=\frac{m_{w} \cdot c_{w}}{K \cdot F+G_{d w} \cdot c_{w}}$; $K_{c w}$ - transfer coefficient of the cooling water, $K_{c w}=\frac{c_{w} \cdot t_{c w}}{K \cdot F+G_{d w} \cdot c_{w}} ; K_{c}$ - transfer coefficient of cans, $K_{c}=\frac{K \cdot F}{K \cdot F+G_{d w} \cdot c_{w}}$.

Fig. 2 - Scheme of modeling of cooling area in MatLab

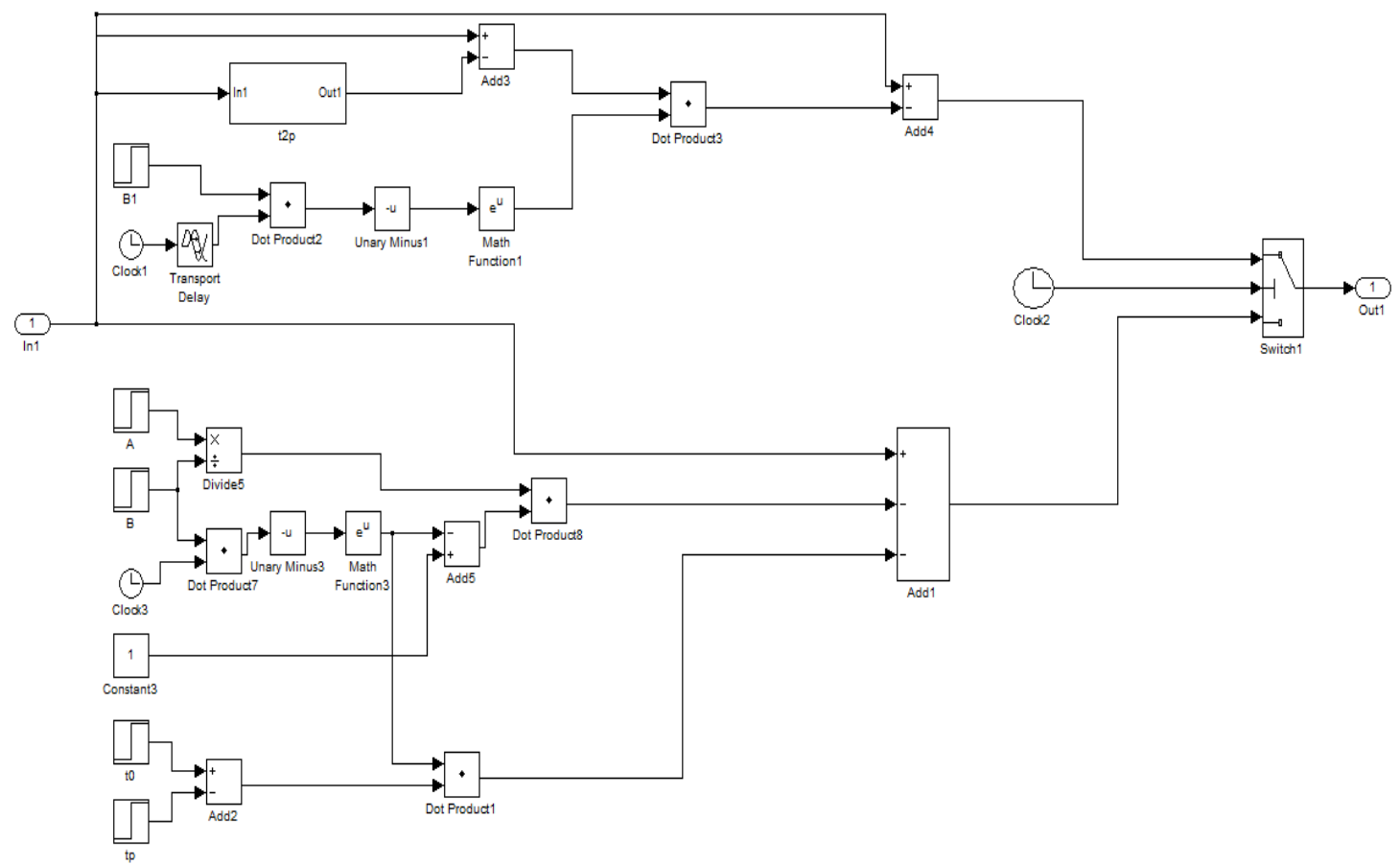

In1 - the water temperature in an autoclave, Out1 - temperature of cans, Switch1 at first transmits the calculated temperature of cans on heating area, and then for shutter area.

Fig. 3 - Scheme of modeling of temperature changes in banks in areas of heating and shutter 


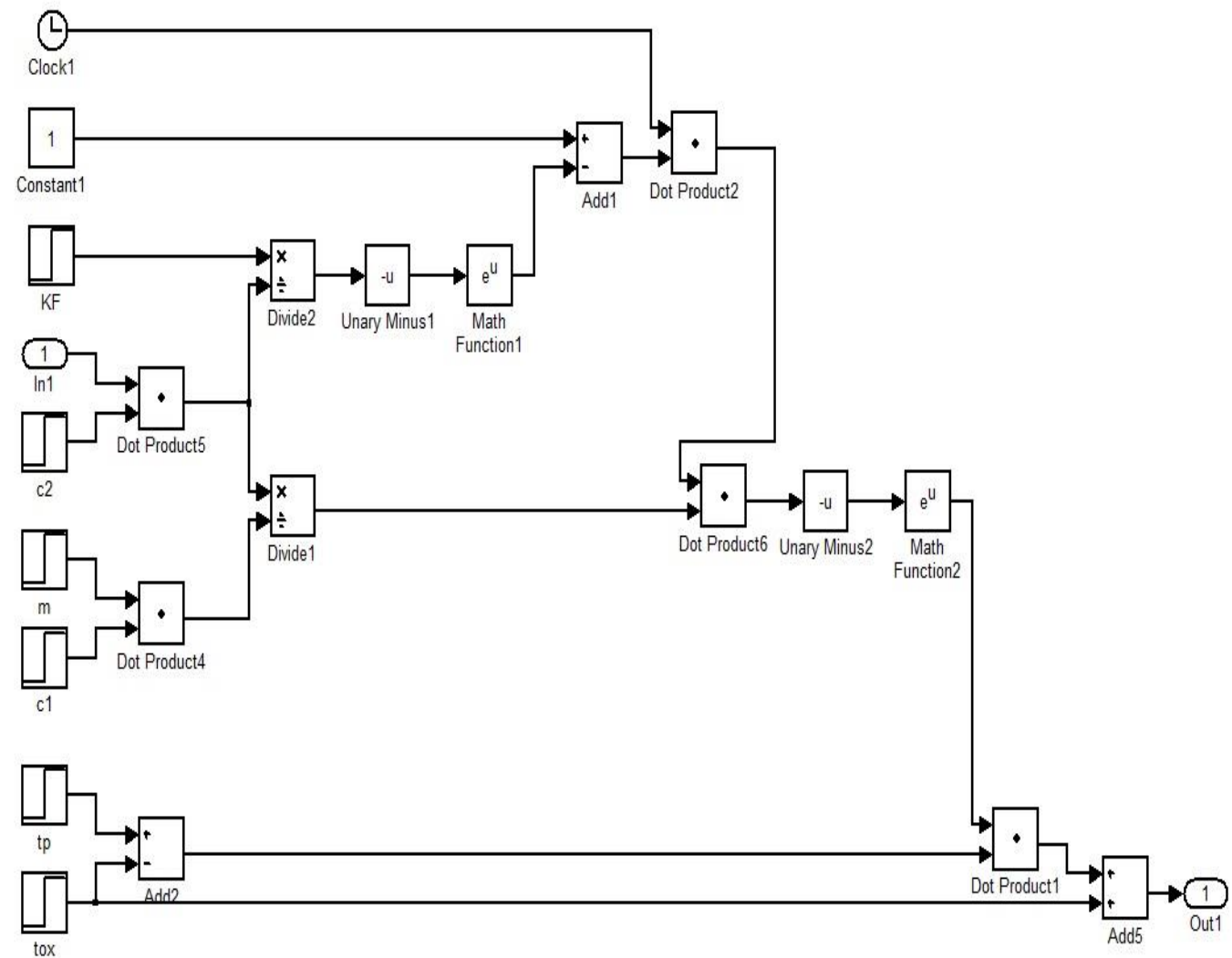

In1 - consumption of cooling water, Out1 - the temperature of cans.

Fig. 4 - Scheme of modeling of temperature changes in the banks in the area of cooling

Results. Dynamic models of change of temperature in an autoclave on heating and shutter areas and on cooling area is developed based on the heat balance equation. Adequacy of models to real process is confirmed by the experiments. Figure 5 shows a comparison of simulation results with the results of other experiments on 25.07 .2012 year.

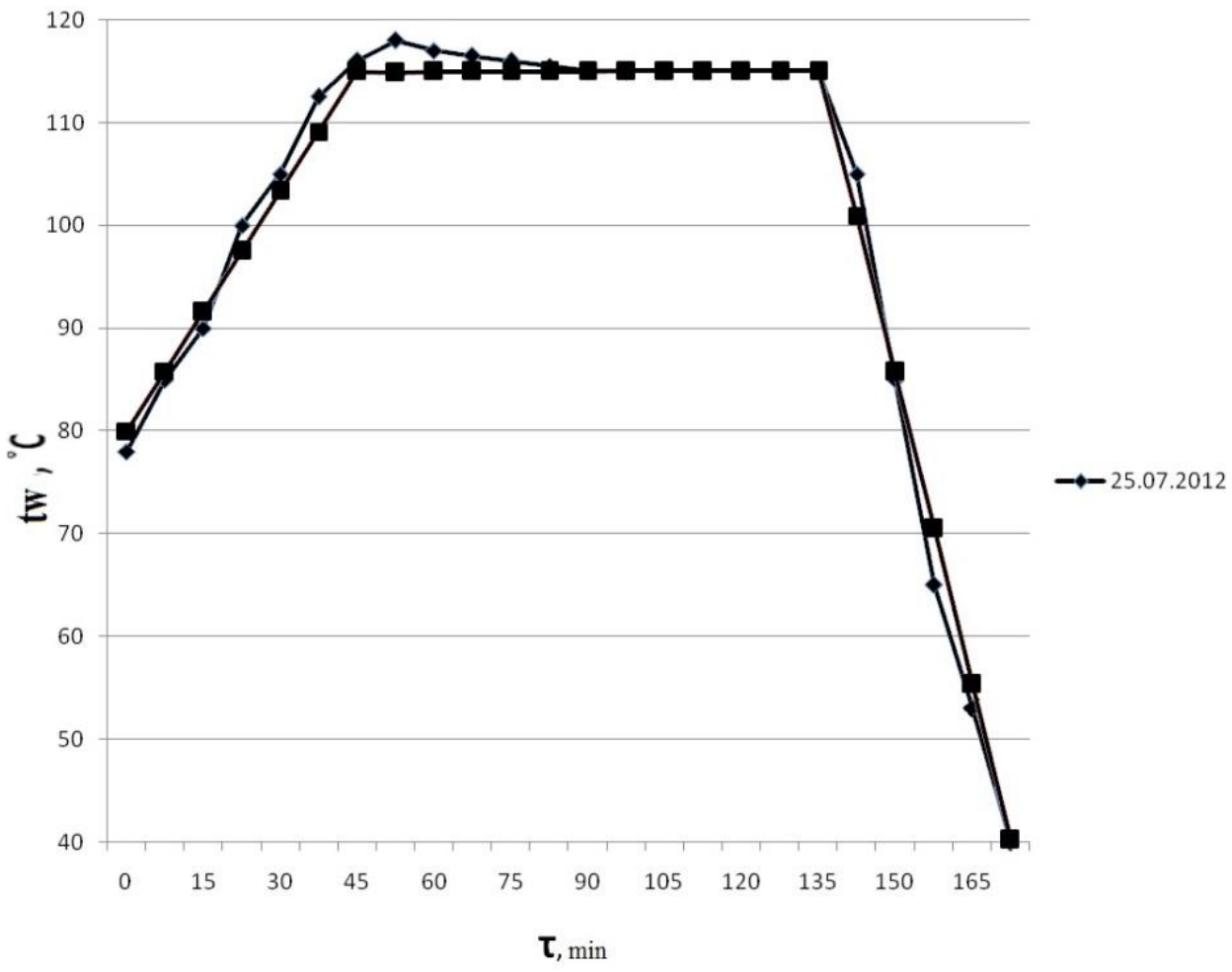

Fig. 5 - Comparison of the calculated and experimental data 


\title{
http://atbp.onaft.edu.ua/
}

The average relative error of simulated values to the values of the real process is less than $4 \%$. The average error for a series of experiments is less than 5\%. Thus, this mathematical model can be used as a dynamic part of LDM of sterilization process in an autoclave.

Conclusions. To build a dynamic model of the autoclave is used existing equation for, decomposition of which under sections provides the ability to use them for process modeling of software controlling of the autoclave. Production experiments confirmed the adequacy of the model the real process.

\section{References}

[1] V. Tregub, "Pobudova matematychnoyi modeli avtomatyzovanoho aparata periodychnoyi diyi," Kharchova Promyslovist, no.3, pp. 165-169, 2004;

[2] S. Ryvkyn and A. Aleksandrov, Termodynamychekye svoystva vodu i vodyanoho para. M.: Enerhoatomyzdat, 1984;

[3] L. Konovalova, Yu. Zahromov, Teoretycheskye osnovy teplotekhnyky. Prymery i zadachy. Tomsk: TPU, 2001;

[4] Farid Golnaraghi and Bendjamin C. Kuo, Automatic control systems. New York: John Wiley\&Sons, 2009.

\section{Література}

[1] Трегуб В. Побудова математичної моделі автоматизованого апарата періодичної дії / В. Трегуб // Харчова промисловість, 2004. - № 3. - С. 165-169.

[2] Ривкин С. Термодинамические свойства воды и водяного пара / С. Ривкин, А. Александров. - М.: Энергоатомиздат, 1984.

[3] Коновалова Л. Теоретические основы теплотехники. Примеры и задачи / Л. Коновалова, Ю. Захромов // Томск: ТПУ, 2001.

[4] Farid Golnaraghi. Automatic control systems / Golnaraghi Farid, C. Kuo Bendjamin // New York: John Wiley\&Sons, 2009.

\section{THE THERMOELECTRIC VACUUM CROCK-POT AND THE AUTOMATED WORKPLACE FOR ITS RESEARCH AS A CONTROL OBJECT}

\author{
S. Hudz ${ }^{1}$, A. Mazur ${ }^{2}$, D. Kovalchuk ${ }^{3}$ \\ ${ }^{1,2,3}$ Odessa National Academy of Food Technologies, Odessa, Ukraine \\ E-mail: ${ }^{1}$ sergogudz@gmail.com
}

Copyright (C) 2014 by author and the journal - Automation technological and business - processes\|. This work is licensed under the Creative Commons Attribution International License (CC BY). http://creativecommons.org/licenses/by/4.0/

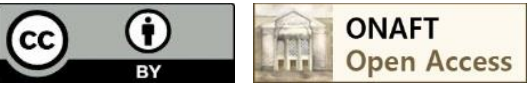

Abstract: The technologies of thermal treatment in vacuum are widely used in various fields of production, in particular in the food industry, but their application at farms, hotels or a for domestic purposes is limited because of the big sizes, high cost of processing equipment and complexity of its management at realization of foodstuff processing. Products, made with use of vacuum technologies, keep much more useful substances because they aren't exposed to high-temperature processing and oxidation while preparation. Development and production of the small-sized equipment for realization of heat treatment processes of foodstuff in vacuum would create technical and economic conditions for implementation of temperature processing processes of foodstuff at farms, hotels and even at home that would promote creation of new food, development of new recipes and, in general, development of the new direction in cookery. So the article describes the problem of equipment construction for the process of thermal processing of food in vacuum such as cooking jam, concentration of juices and dairy products, distillation, drying, pickling, and the possibility of building inexpensive compact vacuum unit for the implementation 